industries in these areas are likely for many years to be unsuitable for investment of Native capital. The establishment of Native towns in Reserves and Purchase Areas was considered to be a development which could not be hastened.

Percy Ibbotson

\title{
The Outlook for Anthropology
}

Professor Daryll Forde, Director of the International African Institute, in his inaugural lecture as Professor of Anthropology at University College, London, took as his subject 'The Outlook for Anthropology'. He suggested that the war, though it had impeded anthropological study and the discussion and interchange of ideas, had at the same time revealed more clearly and urgently the problems to be studied; and anthropologists, at this juncture, should ask themselves what were to be the methods and aim of their studies in the future. Professor Forde referred to the emergence of anthropology as a distinct study in the nineteenth century, as a result of the impact of biological science on the study of the humanities. The early anthropologists had formulated a somewhat grandiose definition of their province, as comprising the study of man, his origins, his behaviour, his various cultures, and the interaction between them. The great vision and the wide objective of these times seemed remote to-day and very far from fulfilment, in spite of the great increase in our knowledge. The intensification of interest and the elaboration of technique had, in fact, resulted in increased specialization and a narrower outlook. Could anthropology resume its role as an integrative study? Professor Forde traced the influence of genetics and comparative anatomy on the study of man's physical and cultural variations and suggested that the physiological factors underlying differences of behaviour were a fruitful subject of study, though not, of course, without reference to the numerous other factors-ecological and social-which were involved. He deprecated any sweeping condemnation of the historical approach and the antagonism which was sometimes assumed between history and science. Historical interpretation of anthropological data was necessary for an understanding of the behaviour of living peoples. Anthropology to-day, he suggested, was tending to develop along two lines - the psychological and the sociological. The former method of approach sought to study the values and the motives underlying man's behaviour, ritual activities, and symbolism; the latter studied behaviour patterns in their social context as expressed in social structure and organization. By a detailed analysis of cultures and their inter-relations anthropology endeavoured to discover processes of wide generality. Such analyses were likely to prove of practical value, not only in relation to problems arising from the impact of western culture on colonial peoples, but also in relation to the tensions which were being revealed in our own society.

\section{School of Oriental and African Studies: University of London}

THE Report of the Governing Body for the year ending July 1946 gives a record of expanding activity in all branches of study. The report of the African department notes that the session $1945-6$ has been the busiest in the history of the department, the number of students reaching 128. A certain number of these have taken short courses in preparation for work as government officials or on land settlement schemes; others have gone to Africa on special research projects, and there have been also a number of social workers. The first group of African students finished their two-year course this session and are returning to their own country to take up work for which their training in London has been a preparation; the most important aspect of this training is considered to be the scientific investigation of their own language, which should lead to a more intelligent teaching of the vernacular.

In June 1947 a number of Colonial Service Probationers are expected to come to the school for intensive language training, and a considerable part of the work of the staff has been concerned with the preparation of these courses. Several African assistants have been recruited for this work. 